W. H. Lin · L. M. Chuang · C. H. Chen · J. I. Yeh •

P. S. Hsieh $\cdot$ C. H. Cheng $\cdot$ Y. T. Chen

\title{
Association study of genetic polymorphisms of SLC2A10 gene and type 2 diabetes in the Taiwanese population
}

Received: 18 September 2005 / Accepted: 30 January 2006 / Published online: 4 April 2006

(C) Springer-Verlag 2006

\begin{abstract}
Aims/hypothesis: The gene encoding solute carrier family 2 , facilitated glucose transporter, member 10 (SLC2A10, previously known as glucose transporter 10 [GLUT10]) is a promising candidate gene for type 2 diabetes since it is highly expressed in liver and pancreas and is located on human chromosome region 20q12-q13.1, a region previously shown to harbour type 2 diabetes susceptibility genes. We investigated whether the $S L C 2 A 10$ gene could be a type 2 diabetes susceptibility gene in the Taiwanese population. Subjects and methods: Sequencing of $S L C 2 A 10$ gene from 48 diabetic subjects detected short tandem repeat polymorphisms in the promoter region, but did not detect any other sequence variants or new singlenucleotide polymorphisms (SNPs) other than those already in the SNPper database (http://snpper.chip.org) (30 June 2005). Results: Using these genetic polymorphisms, we divided the SLC2A10 gene into four distinct linkage disequilibrium blocks and performed a case-control association study in a group of type 2 diabetes subjects $(n=375)$ and normoglycaemic individuals $(n=377)$. The HapD (A-GT-C) haplotype in block 3, a rare haplotype, which consisted of four SNPs (rs3092412, rs2235491, rs2425904 and rs1059217), was modestly associated with type 2 diabetes with a haplotype score of $-2.95567 \quad(p=0.012$ with the
\end{abstract}

W. H. Lin and L. M. Chuang contributed equally to this work.

W. H. Lin · C. H. Chen · P. S. Hsieh •

C. H. Cheng · Y. T. Chen $(\square)$

Institute of Biomedical Sciences, Academia Sinica,

128 Academy Road, Section 2,

Taipei, 11529 Taiwan

e-mail: chen0010@ibms.sinica.edu.tw

Tel.: +886-2-27899104

Fax: $+886-2-27825573$

L. M. Chuang

Department of Internal Medicine,

National Taiwan University Hospital,

Taipei, Taiwan

J. I. Yeh

Graduate Institute of Human Genetics, Tzu Chi University,

Hualien, Taiwan haplotype-specific test). Conclusions/interpretation: Our results suggest that $S L C 2 A 10$ genetic variations do not appear to be major determinants for type 2 diabetes susceptibility in the Taiwanese population.

Keywords GLUT10 · Haplotype · Linkage disequilibrium - Single-nucleotide polymorphism . SLC2A10 - Type 2 diabetes

Abbreviations GLUT10: glucose transporter 10 - LD: linkage disequilibrium - SLC2A10: solute carrier family 2, facilitated glucose transporter, member $10 \cdot$ SNP: single-nucleotide polymorphism - STRP: short tandem repeat polymorphism

\section{Introduction}

Type 2 diabetes is the most common metabolic disorder, affecting at least $5 \%$ of the world's population. Around 150 million people are affected by type 2 diabetes worldwide, and the prevalence is expected to reach 211 million by 2010 [1]. The disease is a result of complex interactions between genetic and environmental factors that regulate insulin sensitivity and/or beta cell function $[2,3]$. Although type 2 diabetes is considered as a polygenic genetic disorder, the number and relative contribution of each of the genetic factors remain to be elucidated [4-6]. Two general approaches are used to search for genetic factors of complex diseases: one is the whole-genome scan to identify chromosomal regions that harbour the genes contributing to type 2 diabetes [7-11], and the other is the case-control association study with biological or positional candidate genes. One such region, 20q13.12, has been mapped for type 2 diabetes in previous studies on Finnish and Ashkenazi Jewish populations and French diabetic families [12-14]. It is believed that a candidate gene non-insulin-dependent diabetes mellitus 3 (NIDDM3) contributes to the development of type 2 diabetes in the $20 \mathrm{q} 13.12$ region. More interestingly, this region has also been mapped for type 2 diabetes in Han Chinese $[15,16]$. 
Table 1 Clinical characteristics (means \pm SD) of type 2 diabetic patients and normoglycaemic controls

\begin{tabular}{lllr}
\hline & Controls $(n=377)$ & Cases $(n=375)$ & $p$ value $^{\mathrm{a}}$ \\
\hline Age (year) & $60.2 \pm 13.3$ & $61.0 \pm 8.7$ & 0.4326 \\
Sex (male:female) & $216: 160$ & $184: 192$ & 0.0154 \\
BMI $\left(\mathrm{kg} / \mathrm{m}^{2}\right)$ & $23.22 \pm 3.17$ & $24.77 \pm 3.30$ & $<0.0001$ \\
Triglycerides $(\mathrm{mmol} / \mathrm{l})$ & $1.30 \pm 0.77$ & $1.72 \pm 0.45$ & $<0.0001$ \\
Cholesterol (mmol/l) & $5.12 \pm 1.02$ & $5.23 \pm 1.07$ & 0.1698 \\
$\mathrm{HbA}_{\mathrm{lc}}(\%)$ & $5.55 \pm 1.04$ & $8.11 \pm 1.59$ & $<0.0001$ \\
\hline
\end{tabular}

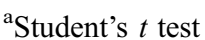

One candidate gene, $H N F 4 A$, is localised in this NIDDM3 region and is associated with type 2 diabetes in Finnish and Ashkenazi Jewish populations [17, 18]. However, the genetic variation of $H N F 4 A$ in promoter 2 region is not associated with type 2 diabetes in the French Caucasian population [19]. It is possible that some genes other than HNF4A within the $20 \mathrm{q} 13.12$ region contribute to the development of type 2 diabetes.

The human facilitative glucose transporters play an important role in maintaining a constant supply of circulating glucose for the body. Defects in facilitative glucose transport have been implicated in the pathogenesis of type 2 diabetes [20-22]. The gene encoding the glucose transporter protein solute carrier family 2, facilitated glucose transporter, member 10 (SLC2A10, previously known as glucose transporter 10 [GLUT10]), lies within the NIDDM3 susceptibility region, and is a novel facilitative glucose transporter that is highly expressed in the liver and pancreas, the two major organs involved in maintaining blood glucose homeostasis [23]. This gene contains five exons and spans at least $28 \mathrm{~kb}$ of genomic DNA [23, 24]. The SLC2A10 protein contains 541 amino acids and shares approximately 20 and $32 \%$ sequence identity with other members (SLC2A3 and SLC2A12, respectively) of the facilitative glucose transporter family. SLC2A10, like other facilitative glucose transporters, contains 12 transmembrane domains, a hydrophilic intracellular loop between helices 6 and 7, and a large extracellular loop containing a potential $\mathrm{N}$-linked glycosylation site between helices 9 and 10 [24, 25]. Recently, a nucleotide variant Ala206Thr in the SLC2A10 gene has been reported to be associated with fasting and post-glucose-load serum insulin concentrations. However, the association of genetic polymorphisms of $S L C 2 A 10$ with type 2 diabetes has been lacking [26]. In this association study in the Taiwanese population, we aimed to identify the genetic variants and linkage disequilibrium (LD) structure of the $S L C 2 A 10$ gene and investigate the role of this gene in type 2 diabetes.

\section{Subjects and methods}

Subjects and phenotype measurements

This study recruited 377 normoglycaemic control subjects whose 75-g OGTTs were normal in a routine physical check-up, and 375 patients with type 2 diabetes diagnosed with the WHO criteria 1998 [27] from the Metabolic Clinic of the National Taiwan University Hospital, Taipei. Both control and case study groups were unrelated. Characteristics of the study subjects, including BMI, triglyceride and cholesterol levels, are summarised in Table 1. Informed consent was obtained from each study subject, and the study protocol was approved by the Institutional Review Board. The concentrations of plasma glucose, total cholesterol and triglyceride were measured in fasting samples by an autoanalyzer (Hitachi 7250 special, Tokyo, Japan). The average $\mathrm{HbA}_{1 \mathrm{c}}$ was $8.11 \pm 1.59 \%$ for the

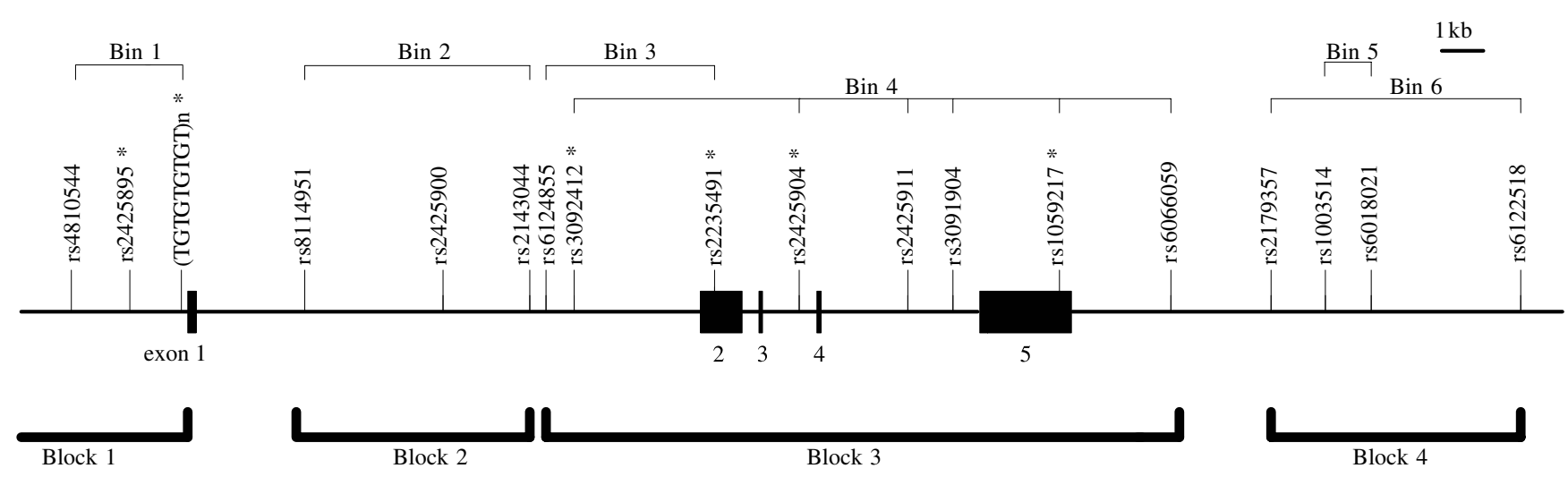

Fig. 1 Graphical representation of SNPs and the STRP (TGTGTGTGT repeat) in relation to the exon-intron structure of the human SLC2A10 gene. The coding regions are shown with filled rectangles. Haplotype blocks 1, 2, 3 and 4 with their boundaries are shown beneath the SNPs. LD bins 1-6 estimated from the data of 94 normoglycaemic subjects are also shown above the SNPs. *SNPs selected for haplotype analysis 
patients with type 2 diabetes and $5.55 \pm 1.04 \%$ for the normal controls.

DNA sequencing and single-nucleotide polymorphism (SNP) genotyping

Genomic DNA was isolated using the PUREGENE DNA purification system (Gentra Systems, Minneapolis, MN, USA). SLC2A10 gene sequence variants were first determined by direct sequencing (Applied Biosystems 3730 DNA Analyzer; PE Applied Biosystems, Foster City, CA, USA) in 48 diabetes subjects. Primers were specifically designed for intron-exon junctions, exons (including all $5^{\prime}$ and $3^{\prime}$ untranslated regions), and a region $1.7 \mathrm{kbp}$ upstream of the transcription start site for the SLC2A10 gene. Primers were designed by the Primer3 PCR primer program (http://fokker.wi.mit.edu/cgi-bin/primer3/ primer3 www.cgi) (30 June 2004). PCRs were performed in a final volume of $40 \mu \mathrm{l}$, containing $0.2 \mu \mathrm{mol} / 1$ of each primer, $50 \mathrm{mmol} / 1$ Tris- $\mathrm{HCl}(\mathrm{pH} \mathrm{9.1)}, 16 \mathrm{mmol} / \mathrm{l} \mathrm{ammo-}$ nium sulphate, $3.5 \mathrm{mmol} / 1 \mathrm{MgCl}_{2}, 0.2 \mathrm{mmol} / 1 \mathrm{dNTPs}$, $4.5 \mu \mathrm{g}$ BSA, $10 \mathrm{ng}$ genomic DNA, and 1.2 units of KlenTaq polymerase (Ab Peptides, St Louis, MO, USA).

Amplification conditions consisted of an initial denaturation of $2 \mathrm{~min}$ at $94^{\circ} \mathrm{C}$, followed by 35 PCR cycles for $40 \mathrm{~s}$ at $94^{\circ} \mathrm{C}, 30 \mathrm{~s}$ at $65^{\circ} \mathrm{C}, 40 \mathrm{~s}$ at $72^{\circ} \mathrm{C}$, and a final 10 -min extension at $72^{\circ} \mathrm{C}$. We then selected 25 SNPs (i.e. rs 2425893 , rs4810544, rs2425895, rs2425897, rs3092211, rs8114951, rs3092439, rs2425900, rs2143044, rs6124855, rs3092412, rs6094438, rs2235491, rs2425904, rs2425911, rs3091904, rs7348121, rs6094446, rs6094447, rs1059217, rs6066059, rs2179357, rs1003514, rs6018021 and rs6122518) from the public SNPper database (http://snpper.chip.org) (30 June 2005) for genotyping in 94 normoglycaemic individuals, to check allele frequency, and performed LD analysis for haplotype block identification.

SNP genotyping was performed using high-throughput matrix-assisted laser desorption and ionisation time-offlight (MALDI-TOF) mass spectrometry (SEQUENOM MassARRAY system; Sequenom, San Diego, CA, USA) [28-30]. On average, $98.2 \%$ of attempted genotypes were successful with MALDI-TOF mass spectrometry. The failure of genotyping was further certified by direct PCR sequencing. Overall, the accuracy of genotyping was $>98 \%$ by more than 3,000 re-sequencing analyses. For genotyping of SNP rs8114951 and rs2425900, PCR products were amplified with the appropriate primers $3233 \mathrm{f}\left(5^{\prime}\right.$-TTTC ACCGTGTTACCCAGGCTGA-3')/3233r $\quad$ (5'-TAAAAT TCAACCTCCCTGTAGCATC-3') and 7699f (5'-AAC CCACCCCATAATTGATCCATC-3')/7699r (5'-GCCAAC ATGGCAAAACCCATCTC-3'), and then sequenced using primer $3233 \mathrm{f}$ and $7699 \mathrm{r}$, respectively.

For genotyping of (TGTGTGTGT) $n$ microsatellite polymorphism in the promoter region, PCR was performed with an FAM-labelled sense primer, GLUT10P1f (5'GTGGTGTCCAAACCCAAG-3'), and antisense primer,
GLU10P2r (5'-GGAAGAGGTGCCCCAATCACT-3'), and then the products were electrophoresed on an ABI Gene Analyzer 3700 system (PE Applied Biosystems). The respective sizes of the (TGTGTGTGT) $n$ repeats were each calculated using GeneScan Analysis software (PE Applied Biosystems). A PCR product size of 172 and 181 suggested the presence of two or three (TGTGTGTGT) $n$ repeats. To confirm the number of (TGTGTGTGT) ${ }_{n}$ repeats further, some of the PCR products were subcloned into pGEM-T vector (Promega, Madison, WI, USA), and purified plasmid DNAs were subjected to sequence analysis.

\section{Statistical analysis}

A Hardy-Weinberg equilibrium proportion test was carried out for cases and controls separately before marker-trait association analysis. An SNP not obeying Hardy-Weinberg equilibrium might be subject to genotype errors. Re-sequencing experiments were then undertaken to verify (or correct) the genotyping results. After re-sequencing correction of genotyping results, all of the SNPs were consistent with Hardy-Weinberg equilibrium in all the subjects except one SNP, rs1003514, which deviated from Hardy-Weinberg equilibrium in the diabetic population. Any significant departure from the Hardy-Weinberg equilibrium proportion test indicates that the assumption of independence between the parental and maternal alleles does not hold and therefore a regular alleletype-based marker-trait association test was replaced by a genotypebased marker-trait association test. All of the above statistics analyses were carried out using SAS/Genetics (2002; SAS Institute, Cary, NC, USA) and were adjusted for age, sex and BMI covariates.

For haplotype construction, genotype data from controls were used to estimate inter-marker LD and define LD blocks. Two inter-marker LD measures, $\mathrm{D}^{\prime}$ and $r^{2}$, for pairs of SNPs were estimated with an expectation-maximisation algorithm implemented in GOLD program [31, 32]. In this study, an LD block was defined by a subset of consecutive SNPs if the measures of inter-marker LD of every pair of those SNPs reached 0.80 or above. A likelihood ratio test implemented in the EH program was performed to test the overall haplotype frequency difference between cases and controls. The Haplo.Score program (http://www.biostat. wustl.edu/genetics/geneticssoft) (20 January 2006) [33] was used to test the global association between the disease status (type 2 diabetes) and haplotypes, and to test the association between the disease status and each haplotype. Simulation $p$ values were computed to avoid the inadequacy of the $\chi^{2}$ distribution for rare haplotypes. Only haplotypes with frequency greater than $2 \%$ were considered in the analysis. Since the above analyses were conducted with each of the haplotypes, a corrected $p$ value was calculated using Bonferroni correction to account for multiple comparisons. A $p$ value of $<0.05$ was considered statistically significant. 


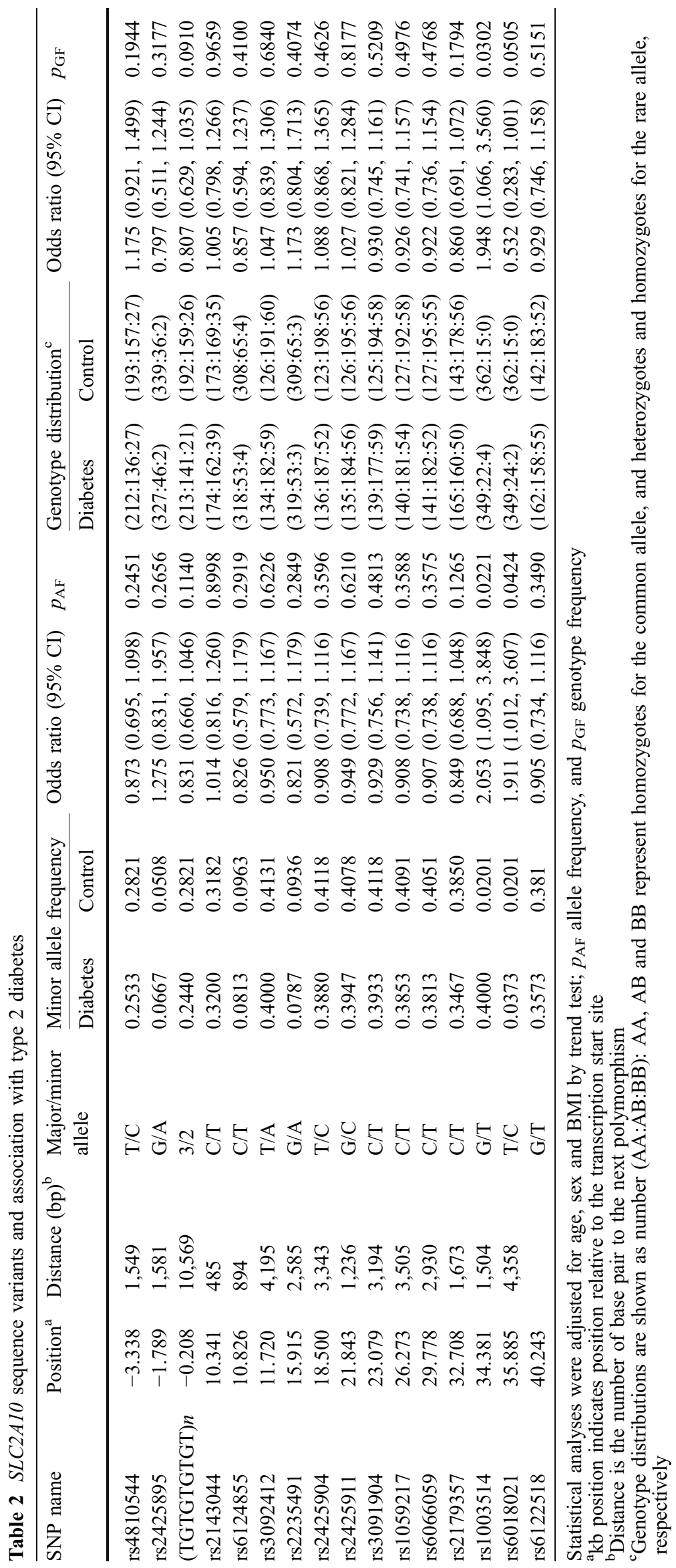




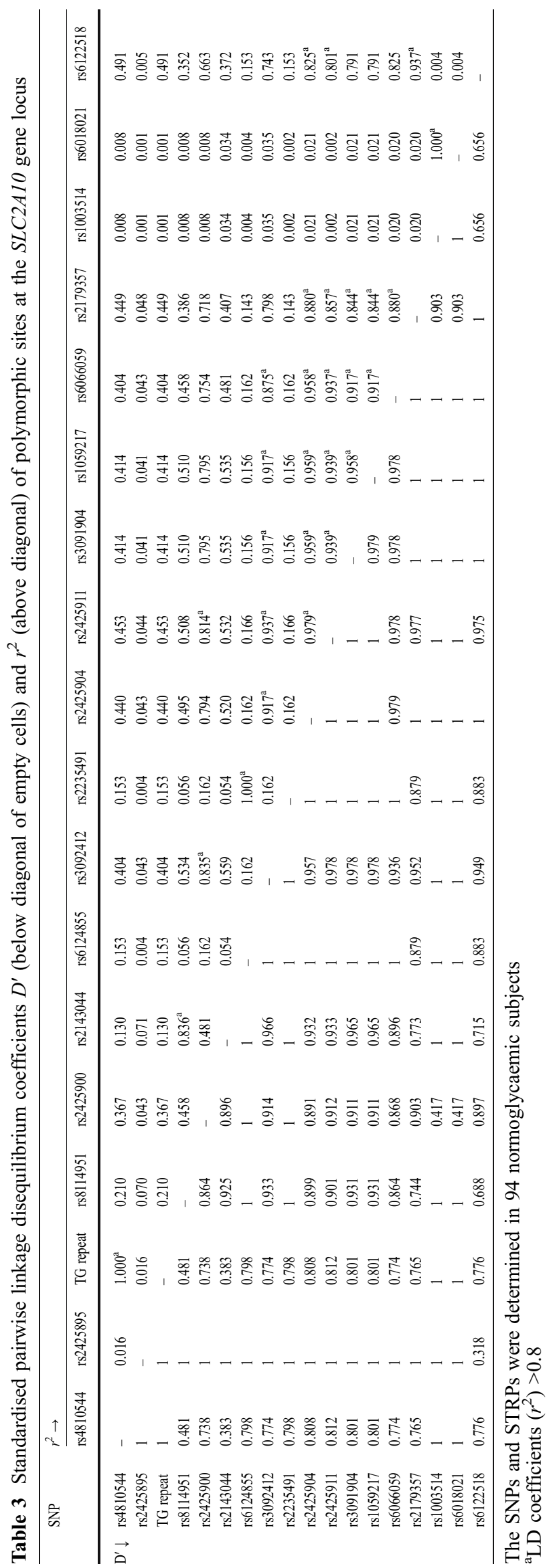




\section{Results and discussion}

To identify sequence variants including SNPs or microsatellite variants in the $S L C 2 A 10$ gene locus, we initially sequenced the promoter region ( $1.7 \mathrm{~kb}$ upstream of exon 1$)$ and all five exons and their flanking intronic sequences in 48 diabetic individuals recruited from the Han Chinese population of Taiwan. The Han Chinese is the largest ethnic group in Taiwan, making up $98 \%$ of the population. We found a tandem repeat sequence variant (TGT GTGTGT) ${ }_{n}$ in the promoter region -291 bp upstream of the translation initiation site. No other sequence variants or new SNPs other than those listed in the SNPper database were found in this re-sequencing effort. We selected 25 SNPs (located between the 5'- and $3^{\prime}$-ends of the SLC2A10 gene) from the SNPper database, studied the allele frequency in 94 normoglycaemic subjects, and constructed an LD block structure. Among the 25 SNPs, eight (rs2425893, rs2425897, rs3092211, rs3092439, rs6094438, rs7348121, rs6094446 and rs6094447) were non-polymorphic in our population and the remaining 17 SNPs and one TGTGTGTGT short tandem repeat polymorphism (STRP) (spanning $43 \mathrm{~kb}$ from the promoter region to $3^{\prime}$ downstream area of this gene [Fig. 1]) were polymorphic with a minor allele frequency of $>0.002$. The average distance between two consecutive SNPs was $2,598 \mathrm{bp}$ ranging from 487 to $4,358 \mathrm{bp}$. The position of all variants (rs4810544-rs6122518 and TG repeat variant) relative to the structure of $S L C 2 A 10$ gene is illustrated in Fig. 1.

We next genotyped 15 SNPs and one STRP in type 2 diabetes patients $(n=375)$ and normoglycaemic controls $(n=377)$. The characteristics of the study subjects, including BMI, triglyceride and cholesterol levels, are summarised in Table 1. The age and cholesterol levels were comparable in cases and controls; however, triglyceride levels and BMI were significantly higher in the diabetic patients than the controls, a characteristic of the diabetes population. There was no significant difference in SNP allele and genotype frequencies between cases and controls and no correlation of the promoter STRP with type 2 diabetes (Table 2). After Bonferroni correction for multiple comparisons, all $p$ values were still insignificant (data not shown). Furthermore, when the promoter activity for different repeat numbers of the TGTGTGTGT sequence was determined, there was no significant difference between two and three repeats of the TGTGTGTGT sequence by an in vitro promoter activity assay (data not shown). These findings were consistent with the result of a recent study in the Finnish population [34]. However, as suggested by the authors, it is possible that some undetected common or rare variants in and around the SLC2A10 gene contribute to the pathogenesis of type 2 diabetes in the examined population. This is supported by the previous report showing that haplotypes produced from rare variants in the promoter and coding regions of angiotensinogen contribute to variation in angiotensinogen levels [35]. We therefore examined the LD structure of the $S L C 2 A 10$ gene.

To determine the extent of LD in the $S L C 2 A 10$ gene, we analysed pairwise $\mathrm{D}^{\prime}$ and $r^{2}$ between the 16 polymorphisms with $>5 \%$ frequency for the minor allele in 94 control samples (Table 3 ). On the basis of linkage analysis using the GOLD program, the SLC2A10 gene appeared to contain four distinct LD blocks extending from the promoter to the $3^{\prime}$-nongenic area (Fig. 1). Block 1 spans about $3.5 \mathrm{~kb}$ from the SNP rs4810544 $(-3,334 \mathrm{bp})$ in the promoter region to the TGTGTGTGT-repeat variant (-291 bp). Block 2 spans $7 \mathrm{~kb}$ in intron 1 starting from SNP rs8114951 to SNP rs2143044. Block 3 spans about $18 \mathrm{~kb}$ in the SLC2A10 gene from SNP rs3092412 in intron 1 to SNP rs6066059 in the 3'-nongenic area. This block region contains almost all the mRNA coding sequence from exon 2 to exon 5. Block 4 of the SLC2A10 gene spans about $7.5 \mathrm{~kb}$ from SNP rs2179357 to SNP rs6122518. Furthermore, we defined several LD bins in the blocks because their genotype data are highly concordant (Fig. 1).

Because of the LD structure, we further examined the association between SNP haplotypes in the different major LD blocks with type 2 diabetes. Only one significant SNP haplotype, the rare haplotype HapD (A-G-T-C) in block 3, exhibited a modest protective effect against type 2 diabetes (HAP-Score $=-2.9557, p=0.012$ with haplotype-specific test) (Table 4). For the complex traits or complex disorders, the rare haplotypes have been recently shown to play a significant role in influencing disease susceptibility and disease endophenotypes [35, 36]. In haplotype-based association analysis, more attention needs to be paid to

Table 4 Association analysis of SLC2A10 haplotypes with type 2 diabetes

\begin{tabular}{|c|c|c|c|c|c|c|c|c|c|c|c|}
\hline \multicolumn{5}{|c|}{ Block 1 haplotypes } & \multicolumn{7}{|c|}{ Block 3 haplotypes } \\
\hline \multirow[t]{2}{*}{ Haplotype } & \multirow[t]{2}{*}{ Composition } & \multicolumn{2}{|c|}{ Frequencies } & \multirow[t]{2}{*}{ HAP-Score } & \multirow[t]{2}{*}{$p^{*}$} & \multirow[t]{2}{*}{ Haplotype } & \multirow[t]{2}{*}{ Composition } & \multicolumn{2}{|c|}{ Frequencies } & \multirow[t]{2}{*}{ HAP-Score } & \multirow[t]{2}{*}{$p^{*}$} \\
\hline & & Control & Case & & & & & Control & Case & & \\
\hline A & G-3 & 0.6653 & 0.6894 & 1.0625 & 0.576 & A & T-G-T-C & 0.5399 & 0.5905 & 1.8442 & 0.261 \\
\hline B & G-2 & 0.2804 & 0.2440 & -1.5806 & 0.228 & $\mathrm{~B}$ & A-G-C-T & 0.2909 & 0.3016 & 0.4290 & 1.000 \\
\hline \multirow[t]{2}{*}{$\mathrm{C}$} & A-3 & 0.0542 & 0.0666 & 0.8256 & 0.818 & $\mathrm{C}$ & A-A-C-T & 0.0692 & 0.0687 & 0.0262 & 1.000 \\
\hline & & & & & & $\mathrm{D}$ & A-G-T-C & 0.0447 & 0.0147 & -2.9557 & 0.012 \\
\hline
\end{tabular}

Haplotype analysis in block 1 using rs2425895 and TG analysis in block 3 using rs3092412, rs2235491, rs2425904 and rs1059217 Haplotypes of $>2 \%$ frequency were tested for association with type 2 diabetes in our patient sample and analysed using the Haplo $\cdot$ Score program

*Statistical analyses were adjusted for age, sex and BMI and all of the $p$ values were corrected by Bonferroni correction 
rare haplotypes, so as to avoid underdetection of a true positive association. Thus, the significant difference in frequency of HapD (A-G-T-C) between cases and controls should be stressed even if the haplotype is not a common one. The association of one of the SNPs (rs2235491) in the HapD haplotype with fasting and oral glucose-induced serum insulin level has been reported [26]. This SNP, located in exon 2, created a non-synonymous change from Ala to Thr at codon 206. However, we could not detect any significant association between the HapD haplotype (or rs2235491 SNP alone) with various quantitative endophenotypes, such as the homeostasis model assessment of insulin resistance, fasting insulin level and the insulin level after glucose loading (data not shown). Thus, the effect of Ala206Thr might be indirectly related to the clinical outcomes, although the exact cause of this discrepancy is not known at present. Another explanation of this discrepancy might be a relatively small sample size as exemplified in the previous study showing a positive association by Andersen et al. [26], which was later shown to be uncorrelated with fasting and glucose-induced insulin levels in the Danish population [37]. Further study will be required to clarify this discrepancy.

In conclusion, we identified four LD blocks distributed in the $S L C 2 A 10$ gene spanning $43 \mathrm{~kb}$ from the promoter to the 3'-nongenic region. The data show that $S L C 2 A 10$ is not a major contributor to type 2 diabetes susceptibility in the Taiwanese population, although we found that one haplotype within LD block 3 showed a protective effect on type 2 diabetes. The variants identified in this study will be useful for future investigations of the role of SLC2A10 in type 2 diabetes susceptibility.

Acknowledgements We thank all the patients for their cooperation in this study. This research project was supported by grants from the National Science \& Technology Program for Genomic Medicine, National Science Council, Taiwan (National Clinical Core and National Genotyping Core), and the Genomics and Proteomics Program, Academia Sinica, Taiwan (to Y. T. Chen), and a grant from the National Science Council, Taiwan (NSC-93-3112-B-002-005 to L. M. Chuang).

\section{References}

1. Amos AF, McCarty DJ, Zimmet P (1997) The rising global burden of diabetes and its complications: estimates and projections to the year 2010. Diabet Med 14(Suppl 5):S1-S85

2. Kahn CR (1994) Banting Lecture. Insulin action, diabetogenes, and the cause of type II diabetes. Diabetes 43:1066-1084

3. Kawate R, Yamakido M, Nishimoto Y, Bennett PH, Hamman RF, Knowler WC (1979) Diabetes mellitus and its vascular complications in Japanese migrants on the Island of Hawaii. Diabetes Care 2:161-170

4. Altshuler D, Hirschhorn JN, Klannemark M et al (2000) The common PPARgamma Pro12Ala polymorphism is associated with decreased risk of type 2 diabetes. Nat Genet 26:76-80

5. Horikawa Y, Oda N, Cox NJ et al (2000) Genetic variation in the gene encoding calpain-10 is associated with type 2 diabetes mellitus. Nat Genet 26:163-175

6. McCarthy MI, Froguel P (2002) Genetic approaches to the molecular understanding of type 2 diabetes. Am J Physiol Endocrinol Metab 283:E217-E225
7. Hanis CL, Boerwinkle E, Chakraborty R et al (1996) A genome-wide search for human non-insulin-dependent (type 2) diabetes genes reveals a major susceptibility locus on chromosome 2. Nat Genet 13:161-166

8. Hanson RL, Ehm MG, Pettitt DJ et al (1998) An autosomal genomic scan for loci linked to type II diabetes mellitus and bodymass index in Pima Indians. Am J Hum Genet 63:1130-1138

9. Duggirala R, Blangero J, Almasy L et al (1999) Linkage of type 2 diabetes mellitus and of age at onset to a genetic location on chromosome 10q in Mexican Americans. Am J Hum Genet 64:1127-1140

10. Elbein SC, Hoffman MD, Teng K, Leppert MF, Hasstedt SJ (1999) A genome-wide search for type 2 diabetes susceptibility genes in Utah Caucasians. Diabetes 48:1175-1182

11. Ehm MG, Karnoub MC, Sakul H et al (2000) Genomewide search for type 2 diabetes susceptibility genes in four American populations. Am J Hum Genet 66:1871-1881

12. Ghosh S, Watanabe RM, Valle TT et al (2000) The FinlandUnited States investigation of non-insulin-dependent diabetes mellitus genetics (FUSION) study. I. An autosomal genome scan for genes that predispose to type 2 diabetes. Am J Hum Genet 67:1174-1185

13. Permutt MA, Wasson JC, Suarez BK et al (2001) A genome scan for type 2 diabetes susceptibility loci in a genetically isolated population. Diabetes 50:681-685

14. Vionnet N, Hani El H, Dupont S et al (2000) Genomewide search for type 2 diabetes-susceptibility genes in French whites: evidence for a novel susceptibility locus for early-onset diabetes on chromosome 3q27-qter and independent replication of a type 2-diabetes locus on chromosome 1q21-q24. Am J Hum Genet 67:1470-1480

15. Zhao JY, Xiong MM, Huang W et al (2005) An autosomal genomic scan for loci linked to type 2 diabetes in northern Han Chinese. J Mol Med 83:209-215

16. Luo TH, Zhao Y, Li G et al (2001) A genome-wide search for type II diabetes susceptibility genes in Chinese Hans. Diabetologia 44:501-506

17. Silander K, Mohlke KL, Scott LJ et al (2004) Genetic variation near the hepatocyte nuclear factor-4 alpha gene predicts susceptibility to type 2 diabetes. Diabetes 53:1141-1149

18. Love-Gregory LD, Wasson J, Ma J et al (2004) A common polymorphism in the upstream promoter region of the hepatocyte nuclear factor-4 alpha gene on chromosome $20 \mathrm{q}$ is associated with type 2 diabetes and appears to contribute to the evidence for linkage in an Ashkenazi Jewish population. Diabetes 53:1134-1140

19. Vaxillaire M, Dina C, Lobbens S et al (2005) Effect of common polymorphisms in the HNF4alpha promoter on susceptibility to type 2 diabetes in the French Caucasian population. Diabetologia 48:440-444

20. Butler PC, Kryshak EJ, Marsh M, Rizza RA (1990) Effect of insulin on oxidation of intracellularly and extracellularly derived glucose in patients with NIDDM. Evidence for primary defect in glucose transport and/or phosphorylation but not oxidation. Diabetes 39:1373-1380

21. Rothman DL, Magnusson I, Cline G et al (1995) Decreased muscle glucose transport/phosphorylation is an early defect in the pathogenesis of non-insulin-dependent diabetes mellitus. Proc Natl Acad Sci USA 92:983-987

22. Li J, Houseknecht KL, Stenbit AE, Katz EB, Charron MJ (2000) Reduced glucose uptake precedes insulin signaling defects in adipocytes from heterozygous GLUT4 knockout mice. FASEB J 14:1117-1125

23. McVie-Wylie AJ, Lamson DR, Chen YT (2001) Molecular cloning of a novel member of the GLUT family of transporters, SLC2a10 (GLUT10), localized on chromosome 20q13.1: a candidate gene for NIDDM susceptibility. Genomics 72: 113-117

24. Dawson PA, Mychaleckyj JC, Fossey SC, Mihic SJ, Craddock AL, Bowden DW (2001) Sequence and functional analysis of GLUT10: a glucose transporter in the type 2 diabetes-linked region of chromosome 20q12-13.1. Mol Genet Metab 74:186-199 
25. Joost HG, Thorens B (2001) The extended GLUT-family of sugar/polyol transport facilitators: nomenclature, sequence characteristics, and potential function of its novel members (review). Mol Membr Biol 18:247-256

26. Andersen G, Rose CS, Hamid YH et al (2003) Genetic variation of the GLUT10 glucose transporter (SLC2A10) and relationships to type 2 diabetes and intermediary traits. Diabetes 52:2445-2448

27. Alberti KG, Zimmet PZ (1998) Definition, diagnosis and classification of diabetes mellitus and its complications. Part 1: diagnosis and classification of diabetes mellitus provisional report of a WHO consultation. Diabet Med 15:539-553

28. Storm N, Darnhofer-Patel B, van den Boom D, Rodi CP (2003) MALDI-TOF mass spectrometry-based SNP genotyping. Methods Mol Biol 212:241-262

29. Jurinke C, van den Boom D, Cantor CR, Koster H (2002) The use of MassARRAY technology for high throughput genotyping. Adv Biochem Eng Biotechnol 77:57-74

30. Hung SI, Chung WH, Liou LB et al (2005) HLA-B*5801 allele as a genetic marker for severe cutaneous adverse reactions caused by allopurinol. Proc Natl Acad Sci USA 102:4134 4139
31. Abecasis GR, Cookson WO (2000) GOLD - graphical overview of linkage disequilibrium. Bioinformatics 16:182-183

32. Terwilliger JD, Ott J (1994) Handbook of human genetic linkage. Johns Hopkins University Press

33. Schaid DJ, Rowland CM, Tines DE, Jacobson RM, Poland GA (2002) Score tests for association between traits and haplotypes when linkage phase is ambiguous. Am J Hum Genet 70:425434

34. Mohlke KL, Skol AD, Scott LJ et al (2005) Evaluation of SLC2A10 (GLUT10) as a candidate gene for type 2 diabetes and related traits in Finns. Mol Genet Metab 85:323-327

35. Zhu X, Fejerman L, Luke A, Adeyemo A, Cooper RS (2005) Haplotypes produced from rare variants in the promoter and coding regions of angiotensinogen contribute to variation in angiotensinogen levels. Hum Mol Genet 14:639-643

36. Liu PY, Zhang YY, Lu Y et al (2005) A survey of haplotype variants at several disease candidate genes: the importance of rare variants for complex diseases. J Med Genet 42:221-227

37. Rose CS, Andersen G, Hamid YH et al (2005) Studies of relationships between the GLUT10 Ala206Thr polymorphism and impaired insulin secretion. Diabet Med 22:946-949 